\title{
ANALISIS VARIASI ARUS PADA HASIL PENGELASAN BAJA KARBON RENDAH DENGAN ELEKTRODA E 7018 TERHADAP KEKUATAN TARIK DAN KEKERASAN JALUR LAS
}

\author{
Irzal, Yudy Hariyadi, dan Syahrul \\ Jurusan Teknik Mesin, Fakultas Teknik, Universitas Negeri Padang \\ Corresponding Author: irzalk3@ft.unp.ac.id
}

\begin{abstract}
Abstrak
Kekuatan hasil lasan dipengaruhi oleh tegangan busur, besar arus, kecepatan pengelasan, besarnya penembusan dan polaritas listrik. Penentuan besarnya arus dalam penyambungan logam menggunakan las busur mempengaruhi efisiensi pekerjaan dan hasil las. Untuk mendapatkan kualitas sambungan yang baik diperlukan penentuan arus yang tepat. Tujuan penelitian ini adalah untuk mengetahui nilai kekuatan tarik dan nilai kekerasan pada plat baja karbon rendah TRS 400 setelah di las menggunakan elektroda E 7018 dengan beberapa variasi arus. Penelitian ini merupakan penelitian eksperimen yang menganalisis kekuatan tarik dan nilai kekerasan hasil pengelasan baja karbon rendah TRS 400 menggunakan variasi tiga arus pengelasan, yaitu: $70 \mathrm{~A}, 80 \mathrm{~A}$, dan $90 \mathrm{~A}$. Spesimen yang digunakan dari bahan yang berupa plat baja TRS 400 dengan ketebalan $8 \mathrm{~mm}$ yang telah di las menggunakan elektroda $\mathrm{E}$ 7018. Hasil penelitian yang telah dilakukan menunjukkan bahwa nilai rata-rata kekuatan tarik dengan menggunakan arus 70 A sebesar 58,43 $\left(\mathrm{kgf} / \mathrm{mm}^{2}\right)$. Arus 80 A sebesar 59,48 $\left(\mathrm{kgf} / \mathrm{mm}^{2}\right)$. Dan arus 90 A sebesar $58,82\left(\mathrm{kgf} / \mathrm{mm}^{2}\right)$, sedangkan rata-rata nilai kekerasan spesimen menggunakan arus 70 A sebesar 182,67 $\left(\mathrm{kg} / \mathrm{mm}^{2}\right)$, 80 A sebesar $190\left(\mathrm{~kg} / \mathrm{mm}^{2}\right)$, dan 90 A sebesar $197\left(\mathrm{~kg} / \mathrm{mm}^{2}\right)$. Hasil pengelasan dengan elektroda E 7018 memiliki kekuatan tarik yang ideal adalah dengan arus pengelasan $80 \mathrm{~A}$, sedangkan nilai kekerasan yang tertinggi terdapat pada kuat arus $90 \mathrm{~A}$.
\end{abstract}

Kata Kunci : Variasi Arus, Kekuatan Tarik, Kekerasan, Pengelasan, E 7018

\begin{abstract}
The strength of the weld results are influenced by the arc voltage, large flow, welding speed, the amount of penetration and electrical polarity. The determination of the flow in the joint metal using arc welding affects the efficiency of the work and welds. To get a good quality joint necessary to determine the proper flow. The purpose of this research was to determine the tensile strength and hardness values on low carbon steel plate TRS 400 after the welding electrodes $E 7018$ with some variation of the flow. This research is an experimental research analyzing the tensile strength and hardness values of low carbon steel welding results TRS 400 using three variations of the welding flow, namely: $70 \mathrm{~A}, 80 \mathrm{~A}$ and $90 \mathrm{~A}$. The specimens were used materials in the form of a steel plate TRS 400 with a thickness of $8 \mathrm{~mm}$ that has been in the welding electrode $E$ 7018. The results have shown that the average value of tensile strength by using flow of $70 \mathrm{~A}$ at $58.43\left(\mathrm{kgf} / \mathrm{mm}^{2}\right)$. The flow of $80 \mathrm{~A}$ amounted to $59.48\left(\mathrm{kgf} / \mathrm{mm}^{2}\right)$. And flow of $90 \mathrm{~A}$ at $58.82\left(\mathrm{kgf} / \mathrm{mm}^{2}\right)$, while the average value of hardness specimens using flow of $70 \mathrm{~A}$ at $182.67\left(\mathrm{~kg} / \mathrm{mm}^{2}\right), 80 \mathrm{~A}$ at $190\left(\mathrm{~kg} / \mathrm{mm}^{2}\right)$, and $90 \mathrm{~A}$ at $197\left(\mathrm{~kg} / \mathrm{mm}^{2}\right)$. Welds with electrode E 7018 has a tensile strength that is ideal with welding flow is $80 \mathrm{~A}$, while the highest hardness value at the flow of $90 \mathrm{~A}$.
\end{abstract}

Keywords: Flow Variation, Tensile Strength, Hardness, Welding, E 7018 


\section{A. Pendahuluan}

Perkembangan teknologi yang berkembang pesat pada saat ini salah satunya adalah pengembangan teknologi dibidang konstruksi yang semakin maju dan tidak dapat dipisahkan dari penggunaan pengelasan karena mempunyai peranan penting dalam rekayasa dan reparasi logam.

Faktor yang mempengaruhi hasil las adalah prosedur pengelasan yaitu perencanaan untuk pelaksanaan yang meliputi cara pembuatan konstruksi las yang sesuai rencana dan spesifikasi dengan menentukan semua hal yang diperlukan dalam pelaksanaan tersebut. Faktor produksi pengelasan adalah jadwal pembuatan, proses pembuatan, alat dan bahan yang diperlukan, urutan pelaksanaan, persiapan pengelasan (meliputi: pemilihan mesin las, penunjukan juru las, pemilihan elektroda, penggunaan jenis kampuh) (Harsono Wiryosumarto, 2008).

Bahan yang mempunyai sifat mampu las yang baik diantaranya adalah baja karbon rendah. Baja ini dapat dilas dengan las busur elektroda terbungkus, las busur rendam dan las MIG (las logam gas mulia). Baja karbon rendah biasa digunakan untuk pelat-pelat tipis dan konstruksi umum (Harsono Wiryosumarto, 2008).

Penyetelan kuat arus pengelasan akan mempengaruhi hasil las. Bila arus yang digunakan terlalu rendah akan menyebabkan sukarnya penyalaan busur listrik. Busur listrik yang terjadi menjadi tidak stabil. Panas yang terjadi tidak cukup untuk melelehkan elektroda dan bahan dasar sehingga hasilnya merupakan rigi-rigi las yang kecil dan tidak rata serta penembusan kurang dalam. Sebaliknya bila arus terlalu tinggi maka elektroda akan mencair terlalu cepat dan akan menghasilkan permukaan las yang lebih lebar dan penembusan yang dalam sehingga menghasilkan kekuatan tarik yang rendah dan menambah kerapuhan dari hasil pengelasan (Syamsul Arifin, 1997). Sama halnya dengan tingkat kekerasan material, apabila arus yang digunakan terlalu rendah maka panas yang dihasilkan tidak menyebabkan terjadinya perubahan struktur pada material sehingga tingkat kekerasan material tidak berubah. Sebaliknya apabila arus yang digunakan terlalu tinggi maka panas yang dihasilkan dapat merubah struktur material, apalagi kalau dibarengi dengan proses pendinginan yang cepat, maka kekerasan material akan meningkat. Oleh sebab itu, pemilihan arus las harus lebih diperhatikan lagi agar menghasilkan kualitas las yang baik.

Kekuatan hasil lasan dipengaruhi oleh tegangan busur, besar arus, kecepatan pengelasan, besarnya penembusan dan polaritas listrik. Penentuan besarnya arus dalam penyambungan logam menggunakan las busur mempengaruhi efisiensi pekerjaan dan bahan las. Penentuan besar arus dalam pengelasan ini diambil 70 A, 80 A dan 90 A. Pengambilan besar arus 70 A dimaksudkan sebagai pembanding dengan interval arus di atas.

\section{B. Metode Penelitian}

Penelitian ini merupakan penelitian eksperimen yang menganalisis kekuatan tarik dan nilai kekerasan hasil pengelasan baja karbon rendah TRS 400 menggunakan variasi tiga arus pengelasan, yaitu: 70 A, 80 A, dan 90 A. Menurut Sugiyono (2008:72) "Metode penelitian eksperimen merupakan metode penelitian yang digunakan untuk mencari pengaruh perlakuan tertentu terhadap yang lain dalam kondisi yang terkendalikan". Dimana hasil pengujian diperoleh melalui percobaan langsung terhadap benda uji. Berdasarkan pokok maslah yang di bahas dalam bab sebelumnya, maka data penelitian berupa hasil pengujian kekuatan tarik dan kekerasan selanjutnya diamati dan di analisa untuk mengetahui ada atau tidaknya pengaruh arus pengelasan terhadap kekuatan tarik dan kekerasan las SMAW dengan elektroda E 7018.

Instrumen pengumpulan data pada penelitian ini adalah melalui tabulasi hasil pengujian dengan aspek penelitian yaitu :

1. Menyiapkan tabel-tabel yang dibutuhkan yang sesuai dengan penelitian yang dilakukan.

2. Mengisi tabel-tabel tersebut dengan data hasil pengujian dan menganalisanya.

Tabel 1. Tabulasi Data Pengujian Tarik

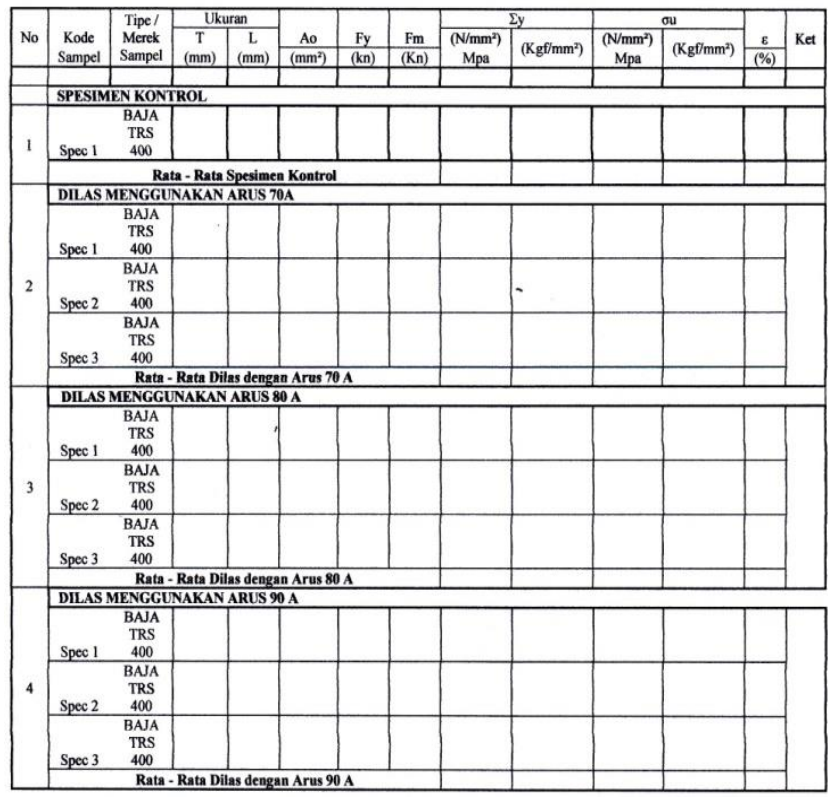

Keterangan:

$$
\begin{aligned}
& >\mathrm{Ao}=\text { Luas Penampang } \\
& >\mathrm{Fm}=\text { Beban Tarik } \\
& >E=\text { Regangan } \\
& >\mathrm{Fy}=\text { Beban Luluh } \\
& >\sigma \mathrm{y}=\text { Kuat Luluh/Batas Ulur } \\
& >\sigma \mathrm{u}=\text { Kuat Tarik Maksimum }
\end{aligned}
$$

Tabel 2. Tabulasi Data Pengujian Kekerasan 


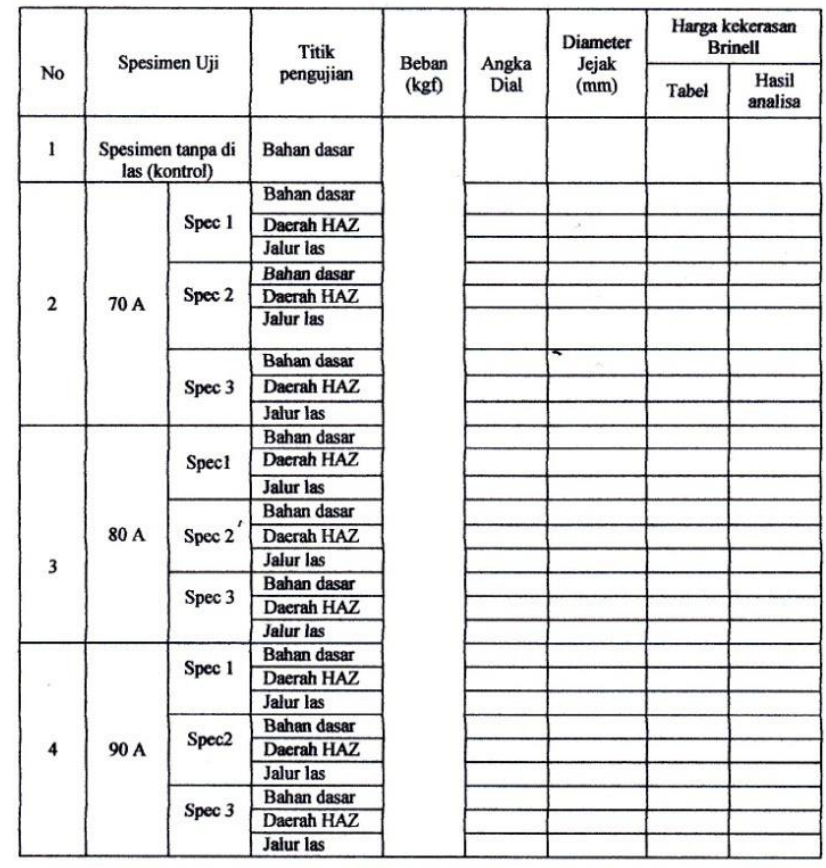

\section{a. Analisa Kekuatan Tarik}

Data yang telah di dapat dari hasil pengujian di susun guna mendapat nilai kekuatan tarik dari masing-masing spesimen. Nilai kekuatan tarik dapat di hitung dengan rumus :

1. Tegangan $(\sigma)$

$$
\sigma=\frac{F}{A o}
$$

Keterangan :

$\sigma=$ Tegangan $\left(\mathrm{N} / \mathrm{m}^{2}\right)$

$\mathrm{F}=$ Gaya $(\mathrm{N})$

Ao $=$ Luas penampang spesimen $\left(\mathrm{m}^{2}\right)$

2. Regangan $(\varepsilon)$

$$
\varepsilon=\frac{L i-L o}{L o} \times 100 \%
$$

Keterangan :

$\varepsilon=$ Regangan

$\mathrm{Li}=$ Panjang spesimen setelah pengujian $(\mathrm{mm})$

Lo $=$ Panjang spesimen sebelum pengujian $(\mathrm{mm})$

3. Modulus Elastis (E)

$$
E=\frac{\sigma}{\varepsilon}
$$

Keterangan :

$\mathrm{E}=$ Modulus Elastisitas $\left(\mathrm{N} / \mathrm{m}^{2}\right)$

$\sigma=$ Tegangan tarik $\left(\mathrm{N} / \mathrm{m}^{2}\right)$

$\varepsilon=$ Regangan

\section{b. Analisa Kekerasan Brinell}

Data yang telah di dapat dari hasil pengujian di susun guna mendapat nilai kekerasan brinell dari masingmasing spesimen. Nilai kekerasan brinell dapat di hitung dengan rumus :

$$
B H N=\frac{2 P}{\pi \cdot D\left(D-\sqrt{D^{2}-d^{2}}\right.}
$$

Dimana :

$\begin{array}{ll}\text { BHN } & \text { : Kekerasan Brinell }\left(\mathrm{kg} / \mathrm{mm}^{2}\right) \\ \mathrm{P} & \text { : Gaya tekan }(\mathrm{kg}) \\ \mathrm{D} & \text { : Diameter bola indentor }(\mathrm{mm}) \\ \mathrm{d} & \text { : Diameter jejak tekan }(\mathrm{mm})\end{array}$

\section{Hasil dan Pembahasan}

\section{Hasil Pengujian Tarik}

Hasil pengujian tarik yang dilaksanakan di laboratorium Kontruksi Jurusan Teknik Sipil Universitas Negeri Padang, maka didapat datadata sebagai berikut :

Tabel 3. Hasil Pengujian Tarik

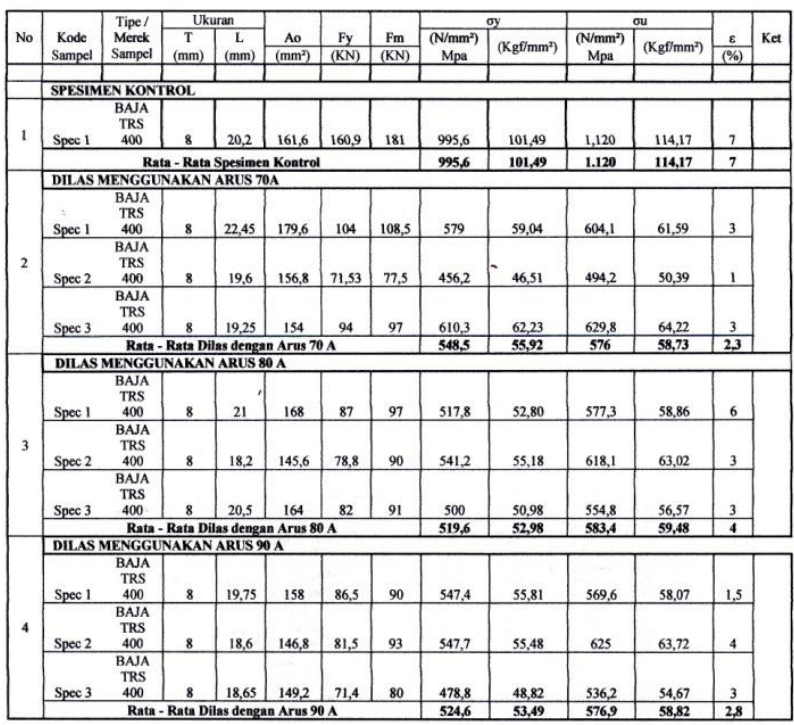

Keterangan:

Ao = Luas Penampang

$\mathrm{Fm}=$ Beban Tarik

$\mathcal{E}=$ Regangan

Fy = Beban Luluh

$\sigma \mathrm{y}=$ Kuat Luluh/Batas Ulur

$\sigma \mathrm{u}=$ Kuat Tarik Maksimum

Setelah melakukan pengujian tarik, maka dapat ditentukan besarnya kekuatan tarik $(\sigma)$ dengan rumus:

Kekuatan tarik $=\frac{\text { gaya terbesar }}{\text { luas penampang awal }}$ atau $\sigma_{\mathrm{B}}=\frac{F}{A o}$

Dimana :

$\sigma=$ Tegangan tarik dalam $\mathrm{kg} / \mathrm{mm}^{2}$

$\mathrm{F}=$ Beban maximum pada waktu pengujian dalam $\mathrm{Kg}$.

Ao $=$ Luas penampang dalam $\mathrm{mm}^{2}$

Perhitungan kekuatan tarik, pada pengujian ini hanya diambil nilai rata-rata dari hasil data spesimen uji tarik dengan menggunakan masing-masing arus pengelasan. 
a. Spesimen Kontrol

Specimen 1:

$\sigma=\frac{F}{A o}=\frac{181 \mathrm{kN}}{161,6 \mathrm{~mm}^{2}}=1.120 \mathrm{~N} / \mathrm{mm}^{2}=114,17 \mathrm{kgf} / \mathrm{mm}^{2}$

b. Arus 70 Amper

Specimen 1:

$\sigma=\frac{F}{A o}=\frac{108,5 \mathrm{kN}}{179,6 \mathrm{~mm}^{2}}=604,1 \mathrm{~N} / \mathrm{mm}^{2}=61,59 \mathrm{kgf} / \mathrm{mm}^{2}$

Specimen 2:

$\sigma=\frac{F}{A o}=\frac{77,5 \mathrm{kN}}{156,8 \mathrm{~mm}^{2}}=494,2 \mathrm{~N} / \mathrm{mm}^{2}=50,39 \mathrm{kgf} / \mathrm{mm}^{2}$ Specimen 3:

$\sigma=\frac{F}{A o}=\frac{97 \mathrm{kN}}{154 \mathrm{~mm}^{2}}=629,8 \mathrm{~N} / \mathrm{mm}^{2}=63,06 \mathrm{kgf} / \mathrm{mm}^{2}$

c. Arus 80 Amper

Specimen 1:

$\sigma=\frac{F}{A o}=\frac{97 \mathrm{kN}}{168 \mathrm{~mm}^{2}}=577,3 \mathrm{~N} / \mathrm{mm}^{2}=58,86 \mathrm{kgf} / \mathrm{mm}^{2}$

Specimen 2:

$\sigma=\frac{F}{A o}=\frac{90 \mathrm{kN}}{145,6 \mathrm{~mm}^{2}}=618,1 \mathrm{~N} / \mathrm{mm}^{2}=63,02 \mathrm{kgf} / \mathrm{mm}^{2}$

Specimen 3:

$\sigma=\frac{F}{A o}=\frac{91 \mathrm{kN}}{164 \mathrm{~mm}^{2}}=554,8 \mathrm{~N} / \mathrm{mm}^{2}=64,22 \mathrm{kgf} / \mathrm{mm}^{2}$

\section{d. Arus 90 Amper}

Specimen 1:

$\sigma=\frac{F}{A o}=\frac{90 \mathrm{kN}}{158 \mathrm{~mm}^{2}}=569,6 \mathrm{~N} / \mathrm{mm}^{2}=58,07 \mathrm{kgf} / \mathrm{mm}^{2}$

Specimen 2:

$\sigma=\frac{F}{A o}=\frac{93 \mathrm{kN}}{148,8 \mathrm{~mm}^{2}}=625 \mathrm{~N} / \mathrm{mm}^{2}=63,72 \mathrm{~kg} / \mathrm{mm}^{2}$

Specimen 3:

$\sigma=\frac{F}{A o}=\frac{80 \mathrm{kN}}{149,2 \mathrm{~mm}^{2}}=536,2 \mathrm{~N} / \mathrm{mm}^{2}=54,67 \mathrm{kgf} / \mathrm{mm}^{2}$

Tabel 4. Hasil rata-rata kekuatan tarik

\begin{tabular}{|c|c|c|c|c|}
\hline \multirow{2}{*}{ Variasi Arus } & \multicolumn{4}{|c|}{ Specimen $\left(\mathrm{kgf} / \mathrm{mm}^{2}\right)$} \\
\cline { 2 - 5 } & 1 & 2 & 3 & Rata-rata \\
\hline Spesimen Kontrol & 114,17 & - & - & 114,17 \\
\hline $70 \mathrm{~A}$ & 61,59 & 50,39 & 64,22 & 58,73 \\
\hline $80 \mathrm{~A}$ & 58,86 & 63,02 & 56,57 & 59,48 \\
\hline $90 \mathrm{~A}$ & 58,07 & 63,72 & 54,67 & 58,82 \\
\hline
\end{tabular}

\section{Pengujian Kekerasan}

Hasil pengujian kekerasan yang dilaksanakan di laboratorium Bahan Teknik Mesin Universitas Negeri Padang, maka didapat data-data sebagai berikut :
Tabel 5. Hasil Pengujian Kekerasan Brinell

\begin{tabular}{|c|c|c|c|c|c|c|c|c|}
\hline \multirow[b]{2}{*}{ No } & \multirow{2}{*}{\multicolumn{2}{|c|}{ Spesimen Uji }} & \multirow{2}{*}{$\begin{array}{c}\text { Titik } \\
\text { pengujian }\end{array}$} & \multirow{2}{*}{$\begin{array}{c}\text { Beban } \\
\text { (kgf) }\end{array}$} & \multirow{2}{*}{$\begin{array}{c}\text { Angka } \\
\text { Dial }\end{array}$} & \multirow{2}{*}{$\begin{array}{c}\text { Diameter } \\
\text { Jejak } \\
(\mathrm{mm})\end{array}$} & \multicolumn{2}{|c|}{$\begin{array}{c}\text { Harga kekerasan } \\
\text { Brinell }\end{array}$} \\
\hline & & & & & & & Tabel & $\begin{array}{c}\text { Hasil } \\
\text { analisa }\end{array}$ \\
\hline 1 & $\begin{array}{r}\text { Spesim } \\
\text { las ( }\end{array}$ & $\begin{array}{l}\text { tanpa di } \\
\text { ntrol) }\end{array}$ & Bahan dasar & \multirow{28}{*}{$\begin{array}{c}187,5 \\
\mathrm{~kg}\end{array}$} & 71 & 0,7 & 318 & 478 \\
\hline \multirow{9}{*}{2} & \multirow{9}{*}{$70 \mathrm{~A}$} & \multirow{3}{*}{ Spec 1} & Bahan dasar & & 64 & 0,8 & 262 & 363 \\
\hline & & & Daerah HAZ & & 60 & 0,8 & 238 & 363 \\
\hline & & & \begin{tabular}{|l|} 
Jalur las \\
\end{tabular} & & 49 & 1 & 186 & 229 \\
\hline & & \multirow{3}{*}{ Spec 2} & Bahan dasar & & 62 & 0,8 & 249 & 363 \\
\hline & & & Daerah HAZ & & 57 & 0,7 & 220 & 478 \\
\hline & & & Jalur las & & 47 & 1 & 179 & 229 \\
\hline & & \multirow{3}{*}{ Spec 3} & Bahan dasar & & 66 & 0,8 & 277 & 363 \\
\hline & & & Daerah HAZ & & 50 & 0,9 & 190 & 285 \\
\hline & & & \begin{tabular}{|l|} 
Jalur las \\
\end{tabular} & & 49 & 1 & 186 & 229 \\
\hline \multirow{9}{*}{3} & \multirow{9}{*}{$80 \mathrm{~A}$} & \multirow{3}{*}{ Spec1 } & Bahan dasar & & 63 & 0,9 & 255 & 285 \\
\hline & & & Daerah HAZ & & 55 & 1 & 210 & 229 \\
\hline & & & \begin{tabular}{|l|} 
Jalur las \\
\end{tabular} & & 50 & 1 & 190 & 229 \\
\hline & & & Bahan dasar & & 65 & 0,9 & 269 & 285 \\
\hline & & Spec 2 & Daerah HAZ & & 57 & 1 & 220 & 229 \\
\hline & & & \begin{tabular}{|l|} 
Jalur las \\
\end{tabular} & & 49 & 1 & 186 & 229 \\
\hline & & & \begin{tabular}{|l} 
Bahan dasar \\
\end{tabular} & & 69 & 0,8 & 301 & 363 \\
\hline & & Spec 3 & \begin{tabular}{|l} 
Daerah HAZ \\
\end{tabular} & & 55 & 1 & 210 & 229 \\
\hline & & & \begin{tabular}{|l|} 
Jalur las \\
\end{tabular} & & 51 & 1 & 194 & 229 \\
\hline \multirow{9}{*}{4} & \multirow{9}{*}{$90 \mathrm{~A}$} & \multirow{3}{*}{ Spec 1} & Bahan dasar & & 69 & 0,9 & 301 & 285 \\
\hline & & & Daerah HAZ & & 52,5 & 0,9 & 200 & 285 \\
\hline & & & \begin{tabular}{|l|} 
Jalur las \\
\end{tabular} & & 52 & 1 & 198 & 229 \\
\hline & & \multirow{3}{*}{ Spec2 } & Bahan dasar & & 67 & 0,8 & 285 & 363 \\
\hline & & & \begin{tabular}{|l} 
Daerah HAZ \\
\end{tabular} & & 58 & 0,9 & 226 & 285 \\
\hline & & & \begin{tabular}{|l|} 
Jalur las \\
\end{tabular} & & 51,5 & 1 & 196 & 229 \\
\hline & & \multirow{3}{*}{ Spec 3} & \begin{tabular}{|l} 
Bahan dasar \\
\end{tabular} & & 69 & 0,8 & 301 & 363 \\
\hline & & & \begin{tabular}{|l} 
Daerah $\mathrm{HAZ}$ \\
\end{tabular} & & 60 & 0,9 & 238 & 285 \\
\hline & & & \begin{tabular}{|l|} 
Jalur las \\
\end{tabular} & & 52 & 1 & 198 & 229 \\
\hline
\end{tabular}

Setelah melakukan pengujian kekerasan, maka dapat ditentukan besarnya kekerasan dengan metode brinell dengan rumus :

Dimana :

$$
B H N=\frac{2 P}{\pi \cdot D\left(D-\sqrt{D^{2}-d^{2}}\right.}
$$

BHN : Kekerasan brinell $\left(\mathrm{kg} / \mathrm{mm}^{2}\right)$

$\mathrm{P} \quad$ : Pembebanan $(\mathrm{kg})$

D : Diameter bola indentor $(\mathrm{mm})$

d : Diameter tapak tekan (mm)

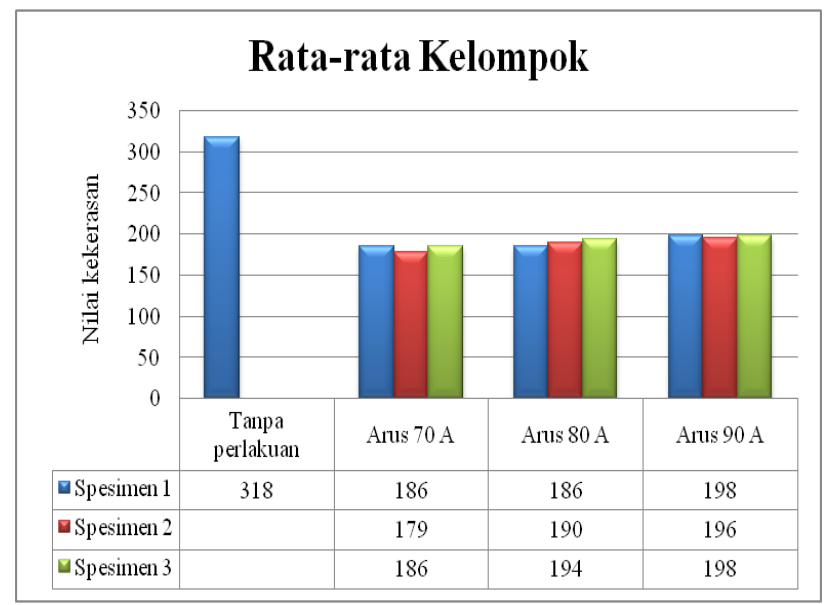

Gambar 1. Grafik Kekerasan Baja TRS 400 Tanpa Perlakuan, dan Setelah Mengalami Pengelasan 


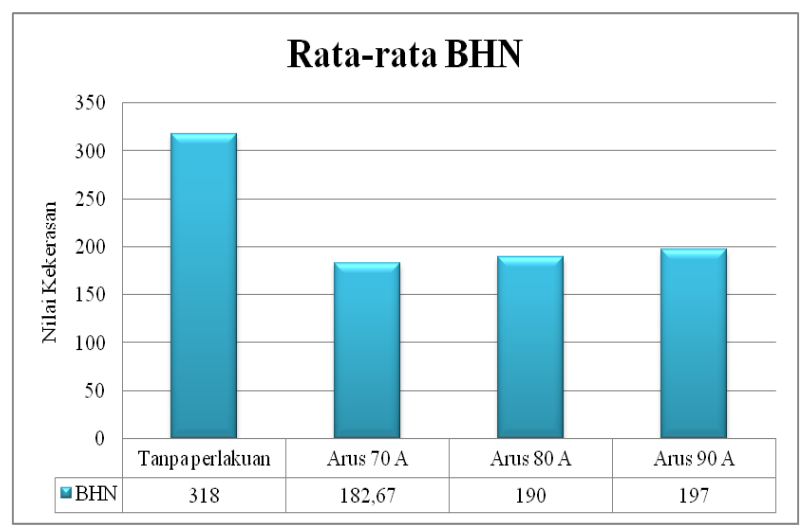

Gambar 2. Grafik Rata-rata Kekerasan Brinell

\section{Kesimpulan}

Berdasarkan analisa data dan pembahasan pada pengujian kekuatan tarik dan kekerasan ini, maka pada penelitian ini dapat diambil kesimpulan bahwa: pengelasan dengan arus $70 \mathrm{~A}, 80 \mathrm{~A}$ dan $90 \mathrm{~A}$, memberikan pengaruh yang berbeda terhadap kekuatan tarik dan kekerasan hasil pengelasan baja karbon rendah (TRS 400) dengan mengunakan las SMAW dengan memakai elektroda E 7018 diameter 3,2 mm.

Pada hasil sambungan las spesimen uji tarik, spesimen putus pada daerah sambungan las. Hasil tersebut menandakan bahwa hasil sambungan las terjadi cacat las karena spesimen putus pada daerah sambungan las, seharusnya spesimen putus pada logam induk yang menandakan bahwa hasil sambungan las tersebut bagus. Kekuatan tarik sambungan las yang di las dengan arus 70 A merupakan kekeuatan tarik yang paling rendah, kekuatan tariknya sebesar 58,73 $\mathrm{kgf} / \mathrm{mm}^{2}$. Kekuatan tarik spesimen dengan menggunakan arus $80 \mathrm{~A}$ sebesar $59,48 \mathrm{kgf} / \mathrm{mm}^{2}$. Dan sambungan las menggunakan arus 90 A memiliki kekuatan tarik sebesar $58,82 \mathrm{kgf} / \mathrm{mm}^{2}$.

Nilai kekerasan sambungan las yang dilas dengan arus 70 A, sebesar $182,67 \mathrm{~kg} / \mathrm{mm}^{2}$. Nilai kekerasan spesimen dengan menggunakan arus 80 A sebesar $190 \mathrm{~kg} / \mathrm{mm}^{2}$. Dan sambungan las menggunakan arus $90 \mathrm{~A}$ memiliki nilai kekerasan yang paling tinggi, yaitu sebesar 197 $\mathrm{kg} / \mathrm{mm}^{2}$.

\section{E. Saran}

Sesuai dengan hasil penelitian ini, maka disarankan beberapa hal sebagai berikut:

1. Dalam melakukan pengelasan sebaiknya juru las memperhatikan arus yang dipakai sesuai dengan tebal benda yang akan di las, tipe elektroda yang digunakan dan diameter elektroda itu sendiri

2. Perlu diadakannya penelitian lebih lanjut mengenai pengaruh kuat arus pengelasan terhadap kekuatan tarik dan kekerasan sehingga hasil yang di dapatkan lebih baik.

\section{Referensi}

Jasman, J., Irzal, I., Adri, J., \& Pebrian, P. (2018). Effect of Strong Welding Flow on the Violence of Low Carbon Steel Results of SMAW Welding with Electrodes 7018. Teknomekanik, 1(1), 24-31. Retrieved from

http://teknomekanik.ppj.unp.ac.id/index.php/t ekno/article/view/9

Harsono Wiryosumarto. (2008). Teknologi Pengelasan Logam. Jakarta: Pradnya Paramita

Nabawi, R. A. (2012). Analisis kekuatan Tarik Komposit Polimer Berpenguat Serat E-glass yang Diberi Perlakuan Alkali (NAOH). Skripsi: Universitas Negeri Padang

Sugiyono. (2008). Metode Penelitian Kuantitatif Kualitatif dan $R \& D$. Bandung: Alfabeta.

Syamsul Arifin. (1997). Las Listrik dan Otogen. Jakarta: Ghalia Indonesia.

Yondri, S., Nabawi, R. A., \& Islami, S. (2017, October). Utilization of Potential Water Energy in Irrigation Channels for PicoHydro Power Plant. In International Conference of Applied Science on Engineering, Business, Linguistics and Information Technology (pp. 161-163). ICo-ASCNITECH.

Yondri, S., Nabawi, R. A., Sunitra, E., Islami, S., \& Asrul, J. (2017, October). The Machine Punch Mulch: A Pneumatic Pierching and Control With Fuzzy Logic Control. In International Conference of Applied Science on Engineering, Business, Linguistics and Information Technology (pp. 148-152). ICoASCNITECH. 